\title{
COMPARAÇÃO ENTRE FLORESTAS DE VÁRZEA E DE TERRA FIRME DO ESTADO DO PARÁ ${ }^{1}$
}

\author{
João Ricardo Vasconcellos Gama ${ }^{2}$, Agostinho Lopes de Souza ${ }^{3}$, Sebastião Venâncio Martins ${ }^{3}$ e \\ Deoclides Ricardo de Souza ${ }^{4}$
}

\begin{abstract}
RESUMO - Foram analisados agrupamentos florísticos entre comunidades arbóreas localizadas em diferentes locais do Estado do Pará, por meio de um banco de dados composto por 24 inventários em florestas de terra firme e 10 em floresta de várzea. Utilizaram-se o índice de Jaccard no cálculo da matriz de similaridade florística, que foi transformada em matriz de distância euclidiana, e o Método de Ward na definição dos grupos. Pelos resultados, foi possível concluir que as composições florísticas das florestas de várzea e terra firme são bem distintas. Poucas espécies ocorrem nos dois ecossistemas; a floresta de terra firme apresenta maior riqueza de espécies arbóreas que a floresta de várzea; houve tendência das florestas de terra firme em se agruparem mais pela situação antrópica e proximidade geográfica do que as florestas de várzea; em geral, as florestas agruparam-se em ordem decrescente de importância dos fatores: saturação hídrica do solo, situação antrópica e proximidade geográfica.
\end{abstract}

Palavras-chave: Similaridade florística, análise de agrupamento e Amazônia.

\section{COMPARISION BETWEEN “VÁRZEA” AND “TERRA FIRME” FORESTS IN THE STATE OF PARA}

\begin{abstract}
Floristic groups among arboreous communities were analyzed in different regions of Pará State, using 34 different forest inventory (24 on "terra firme" and 10 on "várzea" forests) data basis. The Jaccard Index was used to calculate the matrix of floristic similarity, which was turned into a Euclidean matrix of distance, and the Ward Method to define groups. Through the results it was possible to conclude that the floristic composition of varzea and terra firme forests are quite different. Few species occur in both ecosystems; terra firme forest shows a higher tree species richness than varzea forest. There was a cluster tendency of terra firme forests, more related to the anthropic situation and geographic proximity than varzea forests; in general, the forests formed clusters according to a decreasing order of importance, such as: soil hydric saturation, anthropic situation and geographic proximity.
\end{abstract}

Keywords: Floristic similarity, cluster analysis and Amazonia.

\section{INTRODUÇÃO}

Comparações florísticas provenientes de inventários florestais, especialmente entre florestas de grande extensão e com ricas composições, vêm sendo realizadas com bastante freqüência nas Regiões Sudeste e Sul do Brasil. Na Região Norte e mais especificamente no Estado do Pará, destaca-se apenas o trabalho de Almeida (1996), restrito aos manguezais do nordeste paraense. Porém, algumas comparações florísticas mais amplas já englobaram inventários realizados no Pará, podendose citar: Silva e Shepherd (1986), Ratter e Dargie (1992),

\footnotetext{
${ }^{1}$ Recebido em 10.02.2004 e aceito para publicação em 20.04.2005.

${ }^{2}$ Gama Florestal, Trav. Timbó, 1520 - Pedreira, 66085-654 Belém-PA.

${ }^{3}$ Departamento de Engenharia Florestal da UFV, 36570-000 Viçosa-MG.

${ }^{4}$ Departamento de Engenharia Florestal da UFS, 49100-000 Aracajú-SE.
} 
Miranda e Carneiro Filho (1994), Oliveira Filho e Ratter (1995), Montagnini e Muñiz-Miret (1999) e Terborgh e Andresen (1998).

A grande dificuldade em comparar a composição florística das florestas do Estado do Pará, assim como da Amazônia, pode ser atribuída à falta de um banco de dados oriundo de inventário florestal sistemático da flora arbórea da Região Norte. Em muitos locais, tem-se pouca ou nenhuma informação botânica pelo fato de os inventários fitossociológicos terem sido feitos apenas ao longo dos rios e de algumas rodovias importantes (Belém - Brasília, Transamazônica, Cuiabá Santarém e Cuiabá -Porto Velho), embora esses estudos pioneiros tenham contribuído para o aumento do conhecimento da flora regional (ALMEIDA et al., 1993).

A cobertura florestal dos Estados do Pará e da Amazônia como um todo está subdividida - com base no critério fisionômico - em dois subtipos: matas de planície de inundação (terminologia regional - mata de várzea e mata de igapó) e matas de terra firme, além de outras formações como o cerrado e a floresta semiúmida (PANDOLFO, 1978).

A floresta de várzea, cuja vegetação ocorre ao longo dos rios e das planícies inundáveis, normalmente apresenta menor diversidade do que a terra firme e abriga animais e plantas adaptados a condições hidrológicas sazonais (KALLIOLA et al.,1993). A menor diversidade ocorre porque poucas espécies dispõem de mecanismos morfofisiológicos que tolerem o ritmo sazonal de inundação (SILVA et al., 1992).

A terra firme é o ecossistema de maior expressividade e de grande complexidade na composição, distribuição e densidade das espécies. Caracteriza-se pela heterogeneidade florística com predominância de espécies agregadas em algumas formações e aleatórias em outras (ARAÚJO et al., 1986).

Na maior parte dos casos, a exploração florestal no Pará tem ocorrido de forma desordenada, provocando danos significativos à vegetação. Contudo, se a floresta for manejada de modo a gerar o melhor aproveitamento de madeira e produtos florestais não-madeireiros, poderse-á proporcionar o desenvolvimento sustentável para a região. Nesse sentido, estudos de similaridade ou dissimilaridade entre comunidades vegetais, aliados às características estruturais da floresta, permitem inferir sobre a estratificação de unidades básicas de manejo
(BARROS, 1986). Tais estudos são também de grande importância para a gestão dos recursos naturais, como a planificação do manejo e a conservação da biodiversidade (RUOKOLAINEN et al., 1994).

O objetivo deste estudo foi identificar e analisar possíveis agrupamentos entre 34 comunidades florestais situadas em diferentes regiões do Estado do Pará.

\section{MATERIAL E MÉTODOS}

\subsection{Região de estudo}

O Estado do Pará, com superfície de $1.248 .042 \mathrm{~km}^{2}$ ( $15 \%$ do território nacional), possui grande potencial madeireiro, é rico em recursos pesqueiros e possui um dos maiores depósitos minerais do mundo. Entretanto, potencialmente, seu maior recurso natural é a biodiversidade, que está distribuída na cobertura florestal dividida - com base no critério fisionômico - em dois tipos: planície de inundação (mata de várzea e mata de igapó), que representa cerca de $2,7 \%$ do território estadual; e os ecossistemas terrestres $(93,3 \%)$, distribuídos entre florestas de terra firme, formações campestres e áreas de tensão ecológica (DIAS, 1991).

A precipitação média anual varia de $1.600 \mathrm{~mm}$, no sul do estado, a $3.000 \mathrm{~mm}$ no estuário do rio Amazonas, com períodos de estiagem de junho a novembro, estando os valores médios anuais de temperatura entre $25 \mathrm{e}$ $27{ }^{\circ} \mathrm{C}$. Grande parte dos solos do estado (75\%) são Latossolos e Podzólicos distróficos caracterizados por altos níveis de acidez e baixa fertilidade. Os solos férteis e com boa drenagem (Podzólicos eutróficos e Cambissolos) representam menos de $6 \%$ das terras do estado. A planície abrange $58 \%$ de seu território, $28 \%$ da região é composta por terrenos ondulados com altitudes de até 300 m e $14 \%$ ultrapassam os 300 m (DIAS, 1991; SOUZA JR. et al., 1997).

Conforme Souza Jr. et al. (1997), 19\% da área do estado não apresenta estoque de madeira (12\% de áreas desmatadas, 6,3\% de áreas não-florestadas e 0,7\% de áreas ocupadas pelos rios e igarapés); em 29\%, a exploração madeireira já se encontra oficialmente proibida, e $20 \%$ são áreas não protegidas com alta prioridade para a conservação, restando apenas $32 \%$ (400.000 $\mathrm{km}^{2}$ ) consideradas aptas para a atividade madeireira.

No setor florestal, o Estado do Pará se destaca por ser o maior produtor de madeira em tora do Brasil; até 1997 , existiam cerca de 1.300 serrarias extraindo, 
aproximadamente, 13 milhões de $\mathrm{m}^{3}$ de madeira em tora por ano, oriundos de mais de 300 espécies arbóreas (IMAZON, 1998).

\subsection{Banco de dados}

O agrupamento entre fitocenoses arbóreas foi realizado por meio de um banco de dados composto por 34 inventários florestais executados no Estado do Pará (Figura 1), sendo 24 inventários em florestas de terra firme ( 8 em florestas exploradas comercialmente e 16 em florestas não-exploradas comercialmente) e 10 em floresta de várzea (6 em florestas exploradas comercialmente e 4 em florestas não-exploradas comercialmente); todas essas informações foram provenientes de consultas bibliográficas.
O critério de inclusão adotado para inserir a lista florística de um inventário florestal no banco de dados foi diâmetro a 1,30 m do nível do solo (dap) $\geq 4,8 \mathrm{~cm}$ (Quadro 1).

A sinonímia e a grafia dos taxa foram atualizadas mediante consulta ao índice de espécies do Royal Botanic Garden - KEW (1993) e do banco de dados do Missouri Botanical Garden, disponível na página http:// mobot.mobot.org/W3T/ Search/vast.html, sendo as comparações florísticas realizadas em nível de espécie, ou seja, identificações em nível de família e gênero não foram incluídas no banco de dados. O nome das espécies foi digitado e armazenado em um banco de dados estruturado na planilha eletrônica Microsoft Excel 2000.

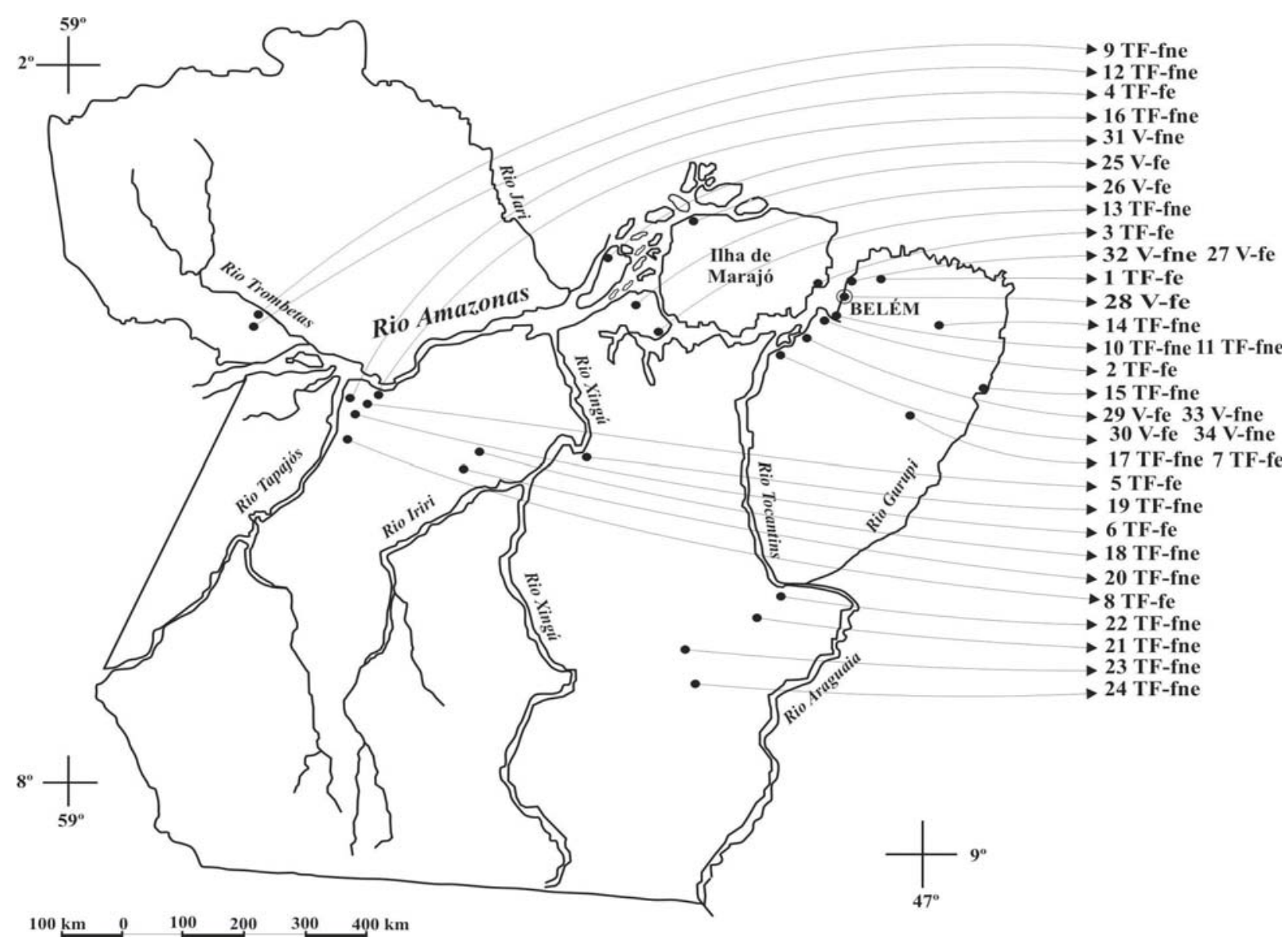

Figura 1 - Localização dos 34 inventários florestais utilizados na análise de agrupamento. Figure 1 - Localization of 34 forest inventories utilized in grouping analysis. 
Quadro 1 - Tipo de vegetação, situação antrópica, localização, tipo de solo, critério de inclusão (CI), número de taxa (NT) e tamanho da amostra (A) das 34 florestas comparadas. Em que: TF = terra firme, $\mathrm{V}=$ várzea, fe $=$ floresta explorada e fne $=$ floresta não-explorada

Table 1 - Type of vegetation, anthropic status, type of soil, inclusion criterium (CI), taxa of number (NT) and sample size (A) of the 34 forests compared, where TF = "terra firme", V= "várzea", fe = explored forest and fne = non-explored forest

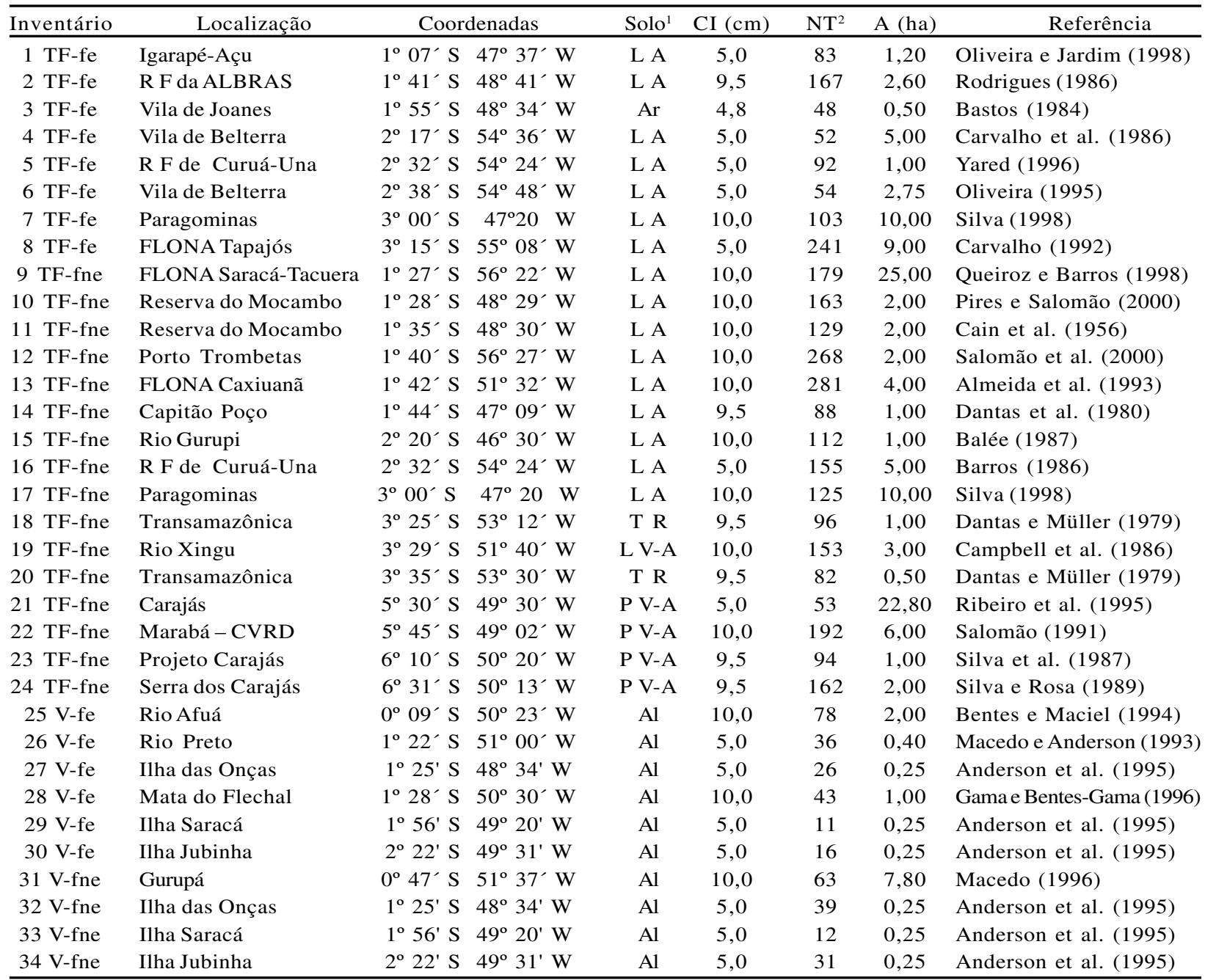

${ }^{1} \mathrm{~L}$ A $=$ Latossolo Amarelo, Ar = arenoso, $\mathrm{T} \mathrm{R}=$ terra roxa, L V-A = Latossolo Vermelho-Amarelo, P V-A = Podzólico Vermelho-Amarelo e $\mathrm{Al}=$ Aluvional.

${ }^{2}$ Número de taxa, em nível de espécie, identificados nos inventários e incluídos no banco de dados deste estudo.

\subsection{Modelo de análise}

A partir da listagem de espécies, calculou-se a matriz de similaridade florística por meio do índice de Jaccard (SJ), que foi transformada em matriz de distância segundo Gama (1980), da seguinte forma: $d_{i j}=\left(1-S_{i j}\right)^{1 /}$ ${ }^{2}$, em que $d_{i j}$ é a medida de distância euclidiana e $S_{i j}$, correspondente coeficiente de similaridade, conforme recomendado por Gama (1980) e Souza et al. (1997) e utilizado por Salomão (1998) e Balduino (2001). Posteriormente, os grupos foram definidos pelo Método de Ward. O processamento foi realizado no programa Statistica/W 5.0 e a seqüência de agrupamentos, apresentada em forma de Dendrograma (Diagrama em Árvore). 


\section{RESULTADOS E DISCUSSÃO}

No total foram listadas 1.257 espécies. Ao se analisar a distribuição das espécies, verificou-se que $85,6 \%$ foram exclusivas de terra firme, $5,2 \%$ foram exclusivas de várzea e 9,2\% ocorreram nas duas tipologias florestais. Esses resultados estão em concordância com o estudo de Ivanauskas et al. (1997), que compararam florestas secas e inundáveis no Estado de São Paulo.

As espécies de maior frequiência em todo o gradiente, ou seja, tanto em floresta de várzea quanto em terra firme, foram: Tapirira guianensis Aubl., que ocorreu em $62 \%$ dos inventários florestais analisados, Inga alba (Sandw.) Willd. (53\%), Hevea brasiliensis (Willd. ex Juss.), M. Arg. (53\%), Sterculia pruriens K. Schum. (50\%), Symphonia globulifera L. (50\%), Carapa guianensis Aubl. (47\%), Virola michelii Heckel (38\%), Inga edulis Mart. (35\%), Guarea kunthiana A. Juss. (35\%), Vatairea guianensis Aubl. (32\%), Licania heteromorpha Benth. (29\%), Sarcaulus brasiliensis (A. DC.), Eyma (29\%), Quararibea guianensis Aubl. (24\%) e Socratea exorrhiza (Mart.) Wendl. (24\%).

Essas espécies ocorreram em mais de três inventários de cada tipologia estudada, portanto apresentam ampla distribuição nas florestas do Estado do Pará. Segundo Ivanauskas et al. (1997), são espécies que possuem mecanismos adaptativos aos diferentes níveis de armazenamento de água no solo, desde o ponto de murcha permanente até a presença de água superficial, ou seja, quando ocorre elevação do nível do rio na época das cheias.

As florestas de terra firme apresentaram 1.192 espécies, sendo 1.076 espécies exclusivas dessa tipologia florestal. As mais freqüentes foram: Dialium guianense (Aubl.) Sandwith, Theobroma speciosum Willd. ex Spreng., Schefflera morototoni (Aubl.) Maguire, Steyerm. \& Frondin., Tachigalia myrmecophila Ducke, Laetia procera (Poepp.) Eichler, Poecilanthe effusa (Huber) Ducke, Trattinnickia rhoifolia Willd., Vitex triflora Vahl., Brosimum guianensis (Aubl.) Huber, Caryocar villosum (Aubl.) Pers., Eugenia patrisii Vahl., Manilkara huberi (Ducke) Standley, Micropholis venulosa Pierre, Protium sagotianum Marchand., Ambelania acida Aubl., Clarisia racemosa Ruiz et Pav., Dipteryx odorata Willd., Enterolobium schomburgkii Benth., Eschweilera odora (Poepp.) Miers., Goupia glabra (Gmel.) Aublet, Hymenolobium excelsum Ducke, Inga heterophylla Willd., Protium altsonii Sandwith, Saccoglotis guianensis Benth., Sapium marmieri Huber e Thyrsodium paraensis Huber.
Uma espécie que, segundo Oliveira (2000), é importante na composição florística e estrutura da floresta de terra firme na Amazônia é Eschwelera coriacea (D.C.) S. A. Mori, que neste trabalho ocorreu em $29 \%$ das florestas inventariadas.

A floresta de várzea apresentou 181 espécies, dentre estas 65 foram exclusivas dessa tipologia florestal. Entre as mais frequientes, destacaram-se: Pterocarpus officinalis Jacq., Astrocaryum murumuru Mart., Matisia paraensis Huber, Theobroma cacao L, Cedrela fissilis Vell., Hura creptans L. e Protium krukoffii Swart.

A Figura 2 representa o dendrograma obtido da análise de agrupamento. Na ordenada estão representados os valores porcentuais de dissimilaridade, quanto mais elevado o nível de agrupamento, menor similaridade entre os membros dos grupos.

A linha Fenon traçada em nível de dissimilaridade de $70 \%$ (30\% de similaridade) possibilitou a formação de dois grupos distintos, constituídos pelas florestas de várzea e terra firme, respectivamente. Essa mesma diferenciação foi obtida por Oliveira-Filho e Ratter (1995) ao compararem, em termos de composição florística, as florestas do Brasil Central com outras grandes formações florestais da América do Sul (trópico-oriental). Resultados similares também foram encontrados por Terborgh e Andresen (1998), que compararam, em nível de famílias, florestas de sete países neotropicais, com ênfase na região amazônica.

A dissimilaridade florística entre florestas de várzea e de terra firme pode ser explicada pelos seguintes fatores (PIRES, 1976; IVANAUSKAS et al., 1997; MONTAGNINI e MUÑIZ-MIRET, 1999): solo - a várzea é formada por terras baixas que margeiam os rios, são áreas planas e de formação sedimentar, por conseguinte apresenta solo mais fértil; Regime de inundação - na várzea ocorre diminuição da troca gasosa entre o solo e o ar, causada pela baixa difusão do oxigênio na água; com isso, o oxigênio é rapidamente consumido e surgem gases como nitrogênio, gás carbônico, hidrogênio e amônia, além de vários outros compostos que podem atingir níveis tóxicos às plantas, o que compromete a germinação das sementes e o desenvolvimento das plantas. Riqueza, diversidade e estrutura arbórea a riqueza, a diversidade e o estoque de biomassa da floresta de várzea são menores, devido à capacidade de adaptação da vegetação de várzea ao regime de inundação.

R. Árvore, Viçosa-MG, v.29, n.4, p.607-616, 2005 


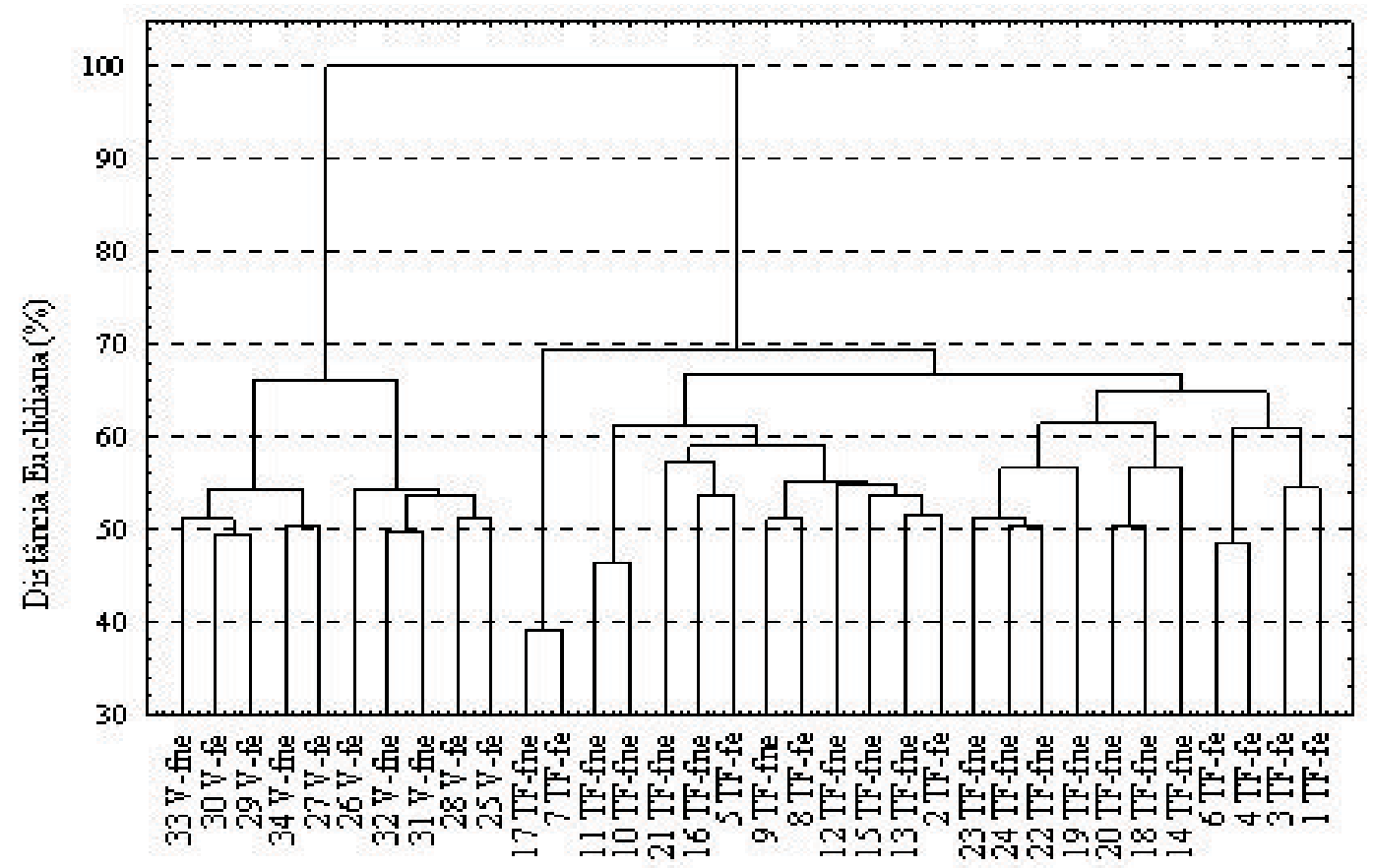

Figura 2 - Dendrograma de dissimilaridade pelo Método de Ward, baseado na distância euclidiana entre as 34 florestas do Estado do Pará.

Figure 2-Dissimilarity dendrogram using the Ward Method, based on Euclidean distance among the 34 forests in the state of Para.

Conforme Pires (1973), Daly e Prance (1989), Amaral et al. (1997) e Montagnini e Muñiz-Miret (1999), quando comparados com a floresta de terra firme, os processos de seletividade de espécies em ecossistema de várzea propiciam menor diversidade, menor amplitude diamétrica, menor estoque de fitomassa, menor altura do dossel e muitos indivíduos com raízes tabulares. Segundo Ivanauskas et al. (1997), a saturação hídrica do solo seria o principal fator atuando na seleção natural das espécies.

Black et al. (1950), Pires (1976), Campbell et al. (1986) e Oliveira (2000) citaram que as florestas da Amazônia apresentam alta diversidade, grande porcentual de espécies raras e baixas similaridades florísticas, mesmo entre locais próximos. Porém, as florestas de terra firme, dos inventários 7 e 17, localizadas no município de Paragominas, destacaram-se por apresentar distância euclidiana de $39 \%$, o que correspondeu a um valor do índice de Jaccard de 0,55, podendo ser consideradas com alta similaridade florística (Mueller-Dombois e Ellenberg, 1974).

R. Árvore, Viçosa-MG, v.29, n.4, p.607-616, 2005
Na floresta de várzea não se observou a formação de grupos devido à proximidade geográfica das florestas, ou seja, não foram as florestas situadas em menores distâncias geográficas que começaram a formar os grupos, sendo essa mesma tendência verificada por Ivanauskas et al. (1997). Na floresta de terra firme, observou-se a tendência de agrupamento das florestas geograficamente mais próximas, tal como as florestas 7 e 17 (Paragominas, PA), 11 e 10 (Reserva do Mocambo, Belém, PA), 16 e 5 (Reserva Florestal de Curuá-Una, PA), 24 e 22 (Carajás, PA, e Marabá, PA), 20 e 18 (Transamazônica, PA) e 6 e 4 (Belterra, PA). Isso demonstra que a proximidade geográfica é um dos fatores que contribuem para o aumento da similaridade florística, entre florestas de terra firme.

Sendo a linha Fenon estabelecida no nível de dissimilaridade de $60 \%$, formaram-se nove grupos: dois em ecossistema de várzea e sete em ecossistema de terra firme. Nesse nível de corte, notou-se não só a influência da proximidade geográfica entre as florestas, mas também a interferência antrópica provocada pela exploração florestal. 
No grupo das florestas de terra firme houve forte tendência de agrupamento de acordo com a situação antrópica, seguida da proximidade geográfica. Tal tendência está evidente na formação dos seguintes grupos: TF-fne 10 e 11; TF-fne 19, 22, 23 e 24; TFfne 14, 18 e 20; TF-fe 4 e 6; e TF-fe 1 e 3 . Esse fato ocorreu, provavelmente, devido à exploração dessas florestas, o que causou sensíveis alterações na composição florística. Carvalho (2002), estudando mudanças na composição florística de uma área na Floresta Nacional do Tapajós, verificou que o número de espécies decresce imediatamente após a exploração. Porém, começa a crescer cinco anos depois e, no final de oito anos, foi maior do que antes da exploração.

Outras variáveis que, provavelmente, contribuíram para a diferenciação florística entre terra firme e várzea foram: altitude - variou de $4 \mathrm{~m}$, em áreas de várzea, até $700 \mathrm{~m}$ em florestas de terra firme localizadas na região de Carajás, PA; temperatura - variou de 25 até $27^{\circ} \mathrm{C}$; e precipitação - aumentou no sentido sul-norte, desde 1.650 até $3.000 \mathrm{~mm}$. Conforme Oliveira-Filho e Fontes (2000), o regime de chuvas, a temperatura e a altitude causam diferenciação significativa entre tipologias florestais.

\section{CONCLUSÕES}

Com base na análise e discussão dos resultados, pode-se concluir que:

- As composições florísticas das florestas de várzea e terra firme são bem distintas; poucas espécies ocorrem nos dois ecossistemas.

- A floresta de terra firme apresenta maior riqueza de espécies arbóreas que a floresta de várzea.

- As florestas de terra firme tenderam a se agrupar mais pela situação antrópica e proximidade geográfica do que as florestas de várzea.

- As florestas se agrupam em ordem decrescente de importância dos fatores: saturação hídrica do solo, situação antrópica e proximidade geográfica.

- Todas as espécies arbóreas requerem um "habitat" específico. Entretanto, a maior parte requer um "habitat" muito específico, determinado pelas condições climática e edáfica, fundamentalmente.

\section{REFERÊNCIAS BIBLIOGRÁFICAS}

ALMEIDA, S.S. Estrutura e florística em áreas de manguezais paraenses: evidências da influência do estuário amazônico. Boletim de Museu Paraense Emílio Goeldi, série Ciência da Terra, v. 8, p. 93-100, 1996.

ALMEIDA, S.S.; LISBOA, P.L.B.; SILVA, A.S.L. Diversidade florística de uma comunidade arbórea na Estação Científica "Ferreira Penna", em Caxiuanã (Pará). Boletim do Museu Paraense Emílio Goeldi, Série Botânica, v.9, n. 1, p. 93-128, 1993.

AMARAL, J.L.; ADIS, J. ; PRANCE, G.T. On the vegetation of a seazonal mixedwater forest near Manaus, Brazilian Amazonia. Amazoniana, v.14, n. 3/4, p. 335-347, 1997.

ANDERSON, A.B. et al. Forest management patterns in the floodplain of the Amazon Estuary. Conservation Biology, v. 9, n. 1, p. 47-61, 1995.

ARAÚJO, A. P.; JORDY FILHO, S.; FONSECA, W. N. A vegetação da Amazônia brasileira. In: SIMPÓSIO DO TRÓPICO ÚMIDO, 1., 1984, Belém. Anais... Belém: EMBRAPA-CPATU, 1986. 493p. p.135-152.(EMBRAPA-CPATU. Documentos, 36).

BALDUINO, A.P.C. Estrutura da vegetação lenhosa de cerrado stricto e sua relação com o solo na Estação Florestal de Experimentação de Paraopeba-MG. 2001. 81f. Dissertação (Mestrado em Ciência Florestal) - Universidade Federal de Viçosa, Viçosa, 2001.

BALÉE, W. A etnobotânica quantitativa dos índios Tembé (rio Gurupi, Pará). Boletim do Museu Paraense Emílio Goeldi, Série Botânica, v. 3, n. 1, p. 29-50, 1987.

BARROS, P.L.C. Estudo fitossociológico de uma floresta tropical úmida no planalto de Curuá-Una, Amazônia brasileira. 1986, 147f. Tese (Doutorado em Ciências Florestais) - Universidade Federal do Paraná, Curitiba, 1986.

R. Árvore, Viçosa-MG, v.29, n.4, p.607-616, 2005 
BASTOS, M.N.C. Levantamento florístico dos campos do Estado do Pará. I - Campo de Joanes (Ilha de Marajó). Boletim do Museu Paraense Emílio Goeldi, Série Botânica, v.1, n. 1/2, p. 67-86, 1984.

BENTES, M.P.M.; MACIEL, U.N. Composição florística, estrutura e multipropósito de espeçies arbóreas de mata de várzea no município de Afuá, Arquipélago de Marajó-PA. Belém: Museu Paraense Emílio Goeldi, Departamento de Botânica, 1994. 30 p.

BLACK, G.A.; DOBZHANSKY, T. H.; PAVAN, C. Some attempts to estimate species diversity and population density of trees in Amazonian forests. Botanical Gazzete, v. 111, n. 4, p.413-425, 1950.

CAIN, S. A. et al. Application of some phytosociological techniques to Brazilian rain forest. American Journal of Botany, v.43, p.911-941, 1956.

CAMPBELL, D.G. et al. Quantitative ecological inventory of terra firma varzea tropical forest on the Rio Xingu, Brazilian Amazon. Brittonia, v.38, n. 4, p.369-393, 1986.

CARVALHO, J.O.P. Changes in the floristic composition of a terra firme rain Forest in Brazilian amazônia over an eight-year period in response to logging. Acta Amazonica, v. 32, n.2, p. 277-291, 2002.

CARVAlho, J.O.P. Structure and dynamics of a logged over Brazilian Amazonian rain forest. 1992. $215 \mathrm{f}$. Thesis (Doctorate in Forestry Science) University of Oxford, Oxford, 1992.

CARVALHO, J.O.P. et al. Composição florística de uma mata secundária no planalto de Belterra no Pará. In: SIMPÓSIO DO TRÓPICO ÚMIDO, 1. , 1984, Belém. Anais... Belém: Embrapa-CPATU, 1984. p. 197-205.

DALY, C.D.; PRANCE, G.T. Brazilian Amazon. In: CAMPBELL, D.G.; HAMMOND D. (Eds). Floristic inventory of tropical countries. New York: NYBG/WWF, 1989. p. 401-426.

R. Árvore, Viçosa-MG, v.29, n.4, p.607-616, 2005
DANTAS, M.; MÜLLER, N.R.M. Estudo fitoecológicos do trópico úmido brasileiro: aspectos fitossociológicos de mata sobre terra roxa na região de Altamira. In: CONGRESSO NACIONAL DE BOTÂNICA, 30., 1979, Campo Grande.

Anais... São Paulo: Sociedade Botânica do Brasil, 1979. p. 205-218.

DANTAS, M.; RODRIGUES, I. A.; MÜLLER, N.R.M. Estudo fito-ecológicos do trópico úmido brasileiro: aspectos fitossociológicos de mata sobre latossolo amarelo em Capitão Poço, Pará. Belém: Embrapa-CPATU, 1980. 19p. (Boletim de Pesquisa, 9).

DIAS, S.F, et al. Zoneamento ecológico econômico do Estado do Pará. Belém: IDESP, 1991. v.1 (IDESP - Estudos Paraenses, 058).

GAMA, J.R.V.; BENTES-GAMA, M.M. Espécies inventariadas na Mata do Flechal. Belém: FCAP-Projeto VÁRZEA, 1996. 7 p.

GAMA, M.P. Bases da análise de grupamentos ("Cluster Analysis"). 1980. 229f. Dissertação (Mestrado em Estatística e Métodos Quantitativos) - Universidade de Brasília, Brasília, 1980.

INSTITUTO DO HOMEM E MEIO AMBIENTE DA AMAZÔNIA - IMAZON. O Pará no século XXI: oportunidade para o desenvolvimento sustentável. Belém: 1998. 83 p.

IVANAUSKAS, N.M.; RODRIGUES, R.R.; NAVE, A.G. Aspectos ecológicos de um trecho de floresta de brejo em Itatinga, SP: florística, fitossociologia e seletividade de espécies. Revista Brasileira de Botânica, v. 20, n.2, p. 139-153, 1997.

KALLIOLA, R.; PUHAKKA, M.; DANJOY, W. Amazonia peruana: vegetación húmeda tropical en el llano sudandino. Finlândia: Gummerus Printing, 1993. 265p.

MACEDO, D.S.; ANDERSON, A.B. Early ecological changes associated with logging in an Amazonian floodplain. Biotropica, v. 25, n. 2, p. 151-163, 1993. 
MACEDO, D.S.M.S. Estrutura e manejo de uma floresta de várzea do estuário amazônico. 1996. 117 f. Dissertação (Mestrado em Ciências Florestais) - Escola Superior de Agricultura “Luiz de Queiroz”, Piracicaba, 1996.

MIRANDA, I. S.; CARNEIRO FILHO, A. Similaridade florística de algumas savanas amazônicas. Boletim do Museu Paraense Emílio Goeldi, Série Botânica, v. 10, n. 2, p. 249-267, 1994.

MONTAGNINI, F.; MUÑIZ-MIRET, N. Vegetation and soils of tidal floodplains of the Amazon estuary: a comparison of varzea and terra firme forests in Pará, Brazil. Journal of Tropical Forest Science, v.11, n.2, p. 420-437, 1999.

MUELLER-DOMBOS, D.; ELLENBERG, G.H. Aims and methods of vegetation ecology. New York: John Wilwy \& Sons, 1974. 547 p.

OLIVEIRA, A.A. Inventários quantitativos de árvores em matas de terra firme: histórico com enfoque na Amazônia brasileira. Acta Amazonica, v. 30, n.4, p. 543-567, 2000.

OLIVEIRA, F.P.M.; JARDIM, M.A.G. Composição florística de uma floresta secundária no município de Igarapé-Açu, Estado do Pará, Brasil. Boletim do Museu Paraense Emílio Goeldi, Série Botânica, v. 14, n. 2, p. 127-145, 1998.

OLIVEIRA, L.C. Dinâmica de crescimento e regeneração natural de uma floresta secundária no Estado do Pará. 1995. 126 f. Dissertação (Mestrado em Ciências Biológicas) - Universidade Federal do Pará, Belém, 1995.

OLIVEIRA-FILHO, A.T.; FONTES, M.A.L. Patterns of floristic differentiation among Atlantic forests in southeastern Brazil and the influence of climate. Biotropica, v. 32, n. 4b, p. 793-810, 2000.

OLIVEIRA-FILHO, A.T.; RATTER, J.A. A study of the origin of central Brazilian forests by the analysis of plant species distribution patterns. Edinburg Journal Botany, v. 52, n. 2, p. 141-194, 1995.

PANDOLFO, C. A floresta amazônica brasileira: enfoque econômico-ecológico. Belém: SUDAM, 1978. 118 p.
PIRES, J.M. Aspectos ecológicos da floresta amazônica. In: CONGRESSO BRASILEIRO DE FLORESTAS TROPICAIS, 2., 1976, Mossoró. Anais... Mossoró: Coleção Mossoroense, 1976. p. 235-287.

PIRES, J.M. Tipos de vegetação da Amazônia. Boletim do Museu Paraense Emílio Goeldi, v.20, p. 179-202, 1973.

PIRES, J.M.; SALOMÃO, R.P. Dinâmica da diversidade arbórea de um fragmento de floresta tropical primária na Amazônia oriental - 1 . Período: 1956 a 1992. Boletim do Museu Paraense Emílio Goeldi, Série Botânica, v. 16, n. 1, p. 63-110, 2000.

QUEIROZ, W. T.; BARROS, A. V. (Coords.). Inventário florestal de $\mathbf{3 . 0 9 7 h a}$ da Floresta Nacional de Saracá-Tacuera, Município de Oriximiná-Pará. Belém: Mineração Rio do Norte: Faculdade de Ciências Agrárias do Pará, 1998. 173 p.

RATTER, J.A.; DARGIE, T. C. D. An analysis of the floristic composition of 26 cerrado áreas in Brazil. Edinburg Journal of Botany, v. 49, p. 235-250, 1992.

RIBEIRO, R.J. et al. Estudo fitossociológico nas regiões de Carajás e Marabá - Pará, Brasil. Acta Amazonica, v. 9, n. 1, p. 47-61, 1995.

RODRIGUES, I.A. Inventário florístico em áreas do projeto Albrás-Alunorte, Barcarena-PA. In: SIMPÓSIO DO TRÓPICO ÚMIDO, 1., 1984, Belém. Anais... Belém: Embrapa-CPATU, 1984. p. 153-166.

ROYAL BOTANIC GARDENS - KEW. Index Kewensis on compact disc-manual. Oxford: Oxford University Press, 1993. 67 p.

RUOKOLAINEN, K. et al. Comparación floristica de doce parcelas en bosque de tierra firme en la Amazonia Peruana. Acta Amazonica, v. 24, n. 1/2, p. 31-48, 1994.

SALOMÃO, A.L.F. Subsídios técnicos para a elaboração do plano de manejo da Floresta Nacional do Rio Preto-ES. 1998. 151f. Tese (Doutorado em Ciência Florestal) - Universidade Federal de Viçosa, Viçosa, 1998.

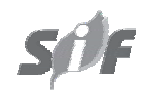

R. Árvore, Viçosa-MG, v.29, n.4, p.607-616, 2005 
SALOMÃO, R.P. Uso de parcelas permanentes para estudos da vegetação florestal. I. Município de Marabá, Pará. Boletim do Museu Paraense Emílio Goeldi, Série Botânica, v.7, n. 2, p. 543-604, 1991.

SALOMÃO, R.P.; ROSA, N.A.; MATOS, A.H. Estudo e monitoramento da florsta tropical primária visando a restauração da paisagem florestal em áreas degradadas da Amazônia brasileira. In: SIMPÓSIO NACIONAL RECUPERAÇÃO DE ÁREAS DEGRADADAS, 4 ., 2000, Blumenau. Anais... Viçosa: SOBRADE, 2000.CD-ROM.

SILVA, A.F.; SHEPHERD, G.J. Comparação florística entre algumas matas brasileiras utilizando análise de agrupamento. Revista Brasileira de Botânica, v. 9, n. 1, p. 81-86, 1986.

SILVA, E.J.V. Impactos da exploração madeireira predatória e planejada sobre o crescimento e diversidade de espécies arbóreas na Amazônia

Oriental. 1998. 81f. Dissertação (Mestrado em Ciências Florestais) - Escola Superior de Agricultura “Luiz de Queiroz”, Piracicaba, 1998.

SILVA, M.F.F.; ROSA, N.A. Análise do estrato arbóreo da vegetação sobre jazidas de cobre na Serra dos Carajás-PA. Boletim do Museu Paraense Emílio Goeldi, série Botânica, v.5, n. 2, p. 175-206, 1989.

R. Árvore, Viçosa-MG, v.29, n.4, p.607-616, 2005
SILVA, M.F.F.; ROSA, N.A.; OLIVEIRA, J. Estudos botânicos na área do Projeto Ferro Carajás. 5. Aspectos florísticos da mata do rio Gelado, Pará. Boletim do Museu Parense Emílio Goeldi, Série Botânica, v. 3, n. 1, p. 1-20, 1987.

SILVA, S. M. et al. Composição florística e fitossociológica do componente arbóreo das florestas ciliares da bacia do rio Tibagi, Paraná: 2. Várzea do rio Bitumirim, Município de Ipiranga, PR. In: CONGRESSO NACIONAL SOBREESSÊNCIAS NATIVAS, 2., 1992, São Paulo. Anais... São Paulo: Instituto Florestal, 1992. p. 192-198.

SOUZA Jr., C. et al. Zoneamento da atividade madeireira na Amazônia: um estudo de caso para o Estado do Pará. Belém: IMAZON, 1997. 23 p. (Série Amazônia, 8).

SOUZA, A.L.; FERREIRA, R.L.C.; XAVIER, A. Análise de agrupamento aplicada à área florestal. Viçosa: Sociedade de Investigações Florestais, 1997. 109 p. (Documento SIF, 16).

TERBORGH, J.; ANDRESEN, E. The composition of Amazonian forests: patterns at local and regional scales. Journal of Tropical Ecology, v. 14, p. 645-664, 1998.

YARED, J.A.G. Efeitos de sistemas silvivulturais na florística e na estrutura de florestas secundárias e primária, na Amazônia oriental. 1996. 179f. Tese (Doutorado em Ciência Florestal) Universidade Federal de Viçosa, Viçosa, 1996. 